Kristin E. Martin (kmarti@uchicago.edu) is the Electronic Resources Management Librarian at the University of Chicago. Kavita Mundle (kavita@uic.edu) is Interim Electronic Resources Librarian and Assistant Catalog Librarian at the University of Illinois at Chicago.

Manuscript submitted September 27, 2013; returned to authors for revision March 19, 2014; revisions submitted May 18, 2014; accepted for publication July 28, 2014.

The authors wish to thank the Association for Library Collections and Technical Services (ALCTS) for providing funds to help defray the costs of a student assistant and subscription to a reference manager. They would like to thank Peggy Johnson and the proposal review committee for giving them the opportunity to provide this review, and thank Mary Beth Weber and the reviewers for providing detailed feedback and improving the paper. The authors would also like to thank Mary Case at the University of Illinois at Chicago Library for providing additional funding to support the research costs. Finally, they would like to extend a special thanks to Vivian Chan for her assistance in searching, collecting, and verifying the myriad references.

\section{Positioning Libraries for a New Bibliographic Universe}

\section{A Review of Cataloging and Classification Literature 2011-12}

\author{
Kristin E. Martin and Kavita Mundle
}

This paper surveys the English-language literature on cataloging and classification published during 2011 and 2012, covering both theory and application. A major theme of the literature centered on Resource Description and Access $(R D A)$, as the period covered in this review includes the conclusion of the RDA test, revisions to RDA, and the implementation decision. Explorations in the theory and practical applications of the Functional Requirements for Bibliographic Records (FRBR), upon which RDA is organized, are also heavily represented. Library involvement with linked data through the creation of prototypes and vocabularies are explored further during the period. Other areas covered in the review include: classification, controlled vocabularies and name authority, evaluation and history of cataloging, special formats cataloging, cataloging and discovery services, non-AACR2/RDA metadata, cataloging workflows, and the education and careers of catalogers.

Cataloging practice is undergoing enormous change as the library com$\checkmark$ munity responds to the development and adoption of a new cataloging code, Resource Description and Access (RDA); the Functional Requirements for Bibliographic Records (FRBR), which is a theoretical model upon which RDA is constructed; and is transitioning into linked data and the Semantic Web. General anxiety and concern about the impending adoption of RDA due to its economic, operational, and technical viability led the three US national libraries - the Library of Congress (LC), the National Library of Medicine (NLM), and the National Agriculture Library (NAL) - to commence a national test of RDA that officially ended in March 2011, and ultimately resulted in the decision to adopt and implement RDA no earlier than January 1, 2013. ${ }^{1}$ This literature review period, 2011-12, thus covers the results of the test by the official RDA test participants who were involved in RDA testing, and the outburst of opinions and preparations regarding the library community's adoption and implementation of RDA. The literature is also full of articles highlighting theoretical and practical experiences with the FRBR family of models, considerations and prototype projects of applying linked data principles to library data, and explorations of data beyond Machine Readable Cataloging (MARC) syntax, which all form the overarching themes of this review. Comparisons between user-contributed 
Table 1. Distribution of Articles in Literature Review

\begin{tabular}{lc}
\hline Area of Literature Review & Number of Articles \\
Cataloging Standards: RDA, FRBR, and BIBFRAME & 136 \\
Linked Data and Bibliographic Data Standards & 127 \\
Controlled Vocabularies and Authority Control & 112 \\
Classification & 37 \\
Bibliographic Control (contains evaluation and history of cataloging; special formats cataloging; discovery services; & 243 \\
non-AACR2/RDA metadata; workflows and cooperative cataloging) & 30 \\
Catalogers: Education and Careers & \\
\hline
\end{tabular}

metadata and subject vocabularies to enhance access to library resources made fine contributions to the existing literature on the topic. Articles related to cataloging as a profession, cataloging history, cataloging education, workflows, and discovery services are explored in a way that depict the developments in and current status of the field and are well represented in the review. Classification using established classification systems and adaptations of those systems continued to be present in the literature.

\section{Method}

The authors began the project by setting up accounts and a group project in Mendeley, a citation management software (www.mendeley.com). The service allows a group of authors to share a set of articles, notes, annotations, and tags. Search terms and tags assigned to articles were tracked using a spreadsheet shared in Google Drive. The authors hired a student to search and upload articles to the private group. Searching was done in Library Literature and Information Science Full Text and Library, Information Science, and Technology Abstracts, and limited to publication years 2011 and 2012 and English language material. The search terms used were: cataloging, bibliographic control, information organization, AACR2, RDA, MARC formats, authority control, classification, Dewey Decimal Classification (DDC), Library of Congress Classification (LCC), subject headings, Library of Congress Subject Headings (LCSH), FRBR, metadata, user contributed metadata, WorldCat, linked data, Dublin Core (DC), batch loading, vendor records, technical services and workflow, technical services and reorganization, and catalog records. The authors also reviewed tables of contents from selected journals that had a scope specific to library technical services to check for any missed articles, reviewed WorldCat for monographic material, and incorporated monographs from book reviews. A total of 1,421 deduplicated citations were entered into Mendeley. The authors read and reviewed the entries, tagged them in appropriate subject areas, and removed citations that were not considered within the scope of the review. Contributions were considered in scope if the focus was on the library practice or theory of bibliographic control, classification, or library standards for organization of information. The authors chose not to include literature on data curation, discovery tools (except as they specifically intersected with cataloging theory and practice), indexing and abstracting issues, and non-descriptive metadata. The authors excluded content with a serials focus because of the existence of a separate literature review on serials published within Library Resources and Technical Services. A total of 481 entries remained, with 267 published in 2011 and 213 published in 2012.

Clearly too many articles to describe within a single review, articles ultimately cited were those with particular significance to an area or representative of a theme in the literature. Many worthwhile contributions were omitted due to space constraints. The articles have been organized into six major categories. Table 1 details the number of articles tagged for each given area. Because many articles were assigned multiple tags, the sum exceeds 481.

\section{Cataloging Standards: RDA and FRBR}

The two most widely discussed topics in the cataloging and classification literature were the new cataloging code, RDA, and the conceptual framework upon which RDA is based, FRBR. Given the significant events that unfolded during the literature review period-the conclusion of the RDA test, revisions to RDA, the decision of the US national libraries to adopt RDA-the emphasis on RDA is not surprising. Papers on RDA included basic descriptions of RDA for the uninitiated, explorations of the differences between RDA and AACR2, results of the test, ideas for implementation, and opinions and concerns for the future. The FRBR family (which includes the Functional Requirements for Bibliographic Records, the Functional Requirements for Authority Data (FRAD), and the Functional Requirements for 
Subject Authority Data (FRSAD)) was also a much debated topic due to its close connection with RDA. Despite FRBR dating to 1998, many articles still began with basic introductions to FRBR, especially for FRAD and FRSAD, which are more recent. FRBR Object Oriented (FRBRoo), first introduced in 2008, was explored in a group of articles. Articles tended to be either theoretical, examining the reasoning and underpinning of the conceptual model, or practical, with empirical articles providing case studies of applying FRBR principles to existing catalog data and practice.

\section{Resource Description and Access (RDA)}

Ever since RDA was released in draft form in 2008 and later online as the RDA Toolkit in 2010, it has received a lukewarm response from the library community due to concerns about its economic, operational, and technical feasibility. ${ }^{2}$ The three US national libraries organized a national test of RDA and the RDA Toolkit from July 2010 to March 2011. In June 2011, they announced their plans to adopt RDA and implement it no sooner than January 2013 with specific recommendations regarding changes to $\mathrm{RDA}$ such as: rewording $\mathrm{RDA}$ in plain English, enhancing and improving functionality of the RDA Toolkit, and coordinating RDA training. ${ }^{3}$ The literature published in 2011 is replete with reports of RDA testing by US academic libraries, public libraries, library schools, and informal testing by various ALCTS committees, of which only a small handful can be covered here. A special theme issue of Cataloging and Classification Quarterly edited by Hall-Ellis and Ellett on RDA testing captures the experiences of test participants, their perspectives on the implementation of $\mathrm{RDA}$, and lessons learned during the process of creating bibliographic description according the new rules of RDA. ${ }^{4}$ Kuhagen relates the details of the training undertaken by LC for the test participants and lessons learned that could be easily applied by other libraries implementing RDA. ${ }^{5}$ Cronin describes the experiences of being an RDA test participant and strategies to fully implement RDA after the test period, emphasizing that at least a brief introduction to FRBR is necessary. ${ }^{6}$ He highlights major issues in managing an RDA implementation, which include staff training, changes in cataloging procedures, preparing an integrated library system for RDA, merging AACR2 and RDA records, display challenges, and the cost effect on outsourced cataloging and authority control. Other articles describe the RDA testing experiences and results among different user communities and resource types, and testing performed by library information science educators. ${ }^{7}$

The RDA Toolkit is a web-based online product that provides RDA text and cataloging-related resources including AACR2, crosswalks between AACR2 and RDA, workflows, and links to Cataloger's Desktop (https://desktop loc.gov). Strengths noted in the literature include easy navigation, a comprehensive table of contents, workflow features, and simple and advanced search features. Drawbacks include the ongoing expense of a subscription to the Toolkit, which is especially a concern for smaller libraries that are unsure about whether they will adopt RDA; problems synchronizing the table of contents to the current location of text in the Toolkit; and the need for multiple windows. ${ }^{8}$ RDA test participants also expressed a lack of confidence in the Toolkit's navigation, searching, and workflow features, and complained that the Toolkit's structure is not intuitive and takes too much time to understand. ${ }^{9}$

Since the development of RDA, the cataloging community has expressed divided opinions on its perceived merits and flaws. Johnson reflects on the experiences of libraries when AACR2 was implemented. ${ }^{10}$ She notes that AACR2 implementation was stressful due to changes in the rules for constructing headings for names and titles, closing the card catalog, and shifting to an online catalog. Randall approaches criticism about RDA, its implementation, and RDA testing optimistically, suggesting that both RDA and AACR2 faced similar economic constraints, technological challenges, and implementation issues. ${ }^{11}$ RDA has been issued as libraries are experimenting with discovery layers to provide seamless access to library metadata while facing economic challenges, waiting for revisions to the wording of the text of RDA, and, most importantly, anticipating MARC's successor. Randall believes that if AACR2 was successfully implemented during its own challenges, the same will happen for RDA.

For catalogers with little or no prior RDA knowledge, Tillett's article sets the context of understanding RDA and FRBR and touches upon all major issues related to RDA. ${ }^{12}$ She offers a general overview of FRBR, provides a history of why RDA was developed, and discusses how RDA can be used as linked data for the Semantic Web. She points out that RDA has an element-based approach that helps differentiate names and relationships that machines can easily use. Readers seeking an introductory book to the cataloging of all types of resources will benefit from reading Welsh and Batley's Practical Cataloguing: AACR2, RDA and MARC 21, and those wanting a focus on e-resources should review Describing Electronic, Digital, and Other Media Using AACR2 and $R D A$ by Weber and Austin. ${ }^{13}$ Both are valuable resources for cataloging materials in RDA and provide an introduction to the FRBR model with numerous examples of how records are created in AACR2 and RDA. Although RDA provides an overarching framework to create consistent bibliographic information, it also provides more flexibility for options and use of cataloger's judgment that could lead to loss of consistency in the catalog. According to McCutcheon, guidance in creating local "best practices" is important for copy catalogers. ${ }^{14}$ He provides descriptions of field-by-field instructions 
for copy catalogers to review MARC records in RDA, particularly monographs, to ensure consistency in the catalog.

\section{FRBR Family}

It has been over a decade since FRBR was developed yet the community is still struggling to grasp it as an acceptable model. A special issue of Cataloging and Classification Quarterly edited by Smiraglia on the "The FRBR Family of Models" contributes extensively to the debate, research, and analysis surrounding FRBR. ${ }^{15}$ Papers in this issue explore the FRBR family of models including FRAD, FRSAD, and FRBRoo. The major themes are FRBR implementation studies; FRBR extension studies; FRBR and cataloging code; and the connection between FRBR, linked data, and the Semantic Web. These studies offer deeper interpretations and understandings of issues related to FRBR and attempt to answer the question: is FRBR still relevant today, especially in the world of linked data?

Smiraglia draws attention to some of the major problems or lacunae of FRBR-identification and definition of entities "work" and "expression."16 $\mathrm{He}$ comments that the problem of inherent hierarchical sequence of work, expression, manifestation, and item in FRBR weakens the applicability of FRBR to the complex universe of bibliographic data. He questions whether it is pragmatic to construct future catalogs around the idea of "work." FRBR, when developed more than a decade ago as a conceptual model, was believed to provide structure and format to the library catalog. Technology now allows for the transfer of library records in RDF format and in linked data format without FRBRizing catalogs. Le Bouef, in the foreword to the special issue, urges the library community to consider the reformulation of FRBR with the object-oriented definition FRBRoo. ${ }^{17}$ In 2009, an international working group harmonized two conceptual models, FRBR and the Comité International pour la Documentation Conceptual Reference Model (CIDOC-CRM - a model developed in 1996 by the museum community) into now what is known as FRBRoo. ${ }^{18}$ Thus, in Le Bouef's estimation, in the last fourteen years FRBR has metamorphosed into the current pinnacle of FRBRoo, promising a new future for bibliographic data.

The use of FRBR principles in RDA has become a focal point of many debates. Taniguchi examined how RDA implements the FRBR and FRAD models and how it differs from FRBR while it specifies relationships between works and manifestations. ${ }^{19}$ The author proposes a new model for FRAD to better reflect RDA. Riva and Oliver offer an in-depth review of the extent of RDA alignment and divergence with FRBR and FRAD with respect to user tasks, entities, attributes, and relationships. ${ }^{20}$ RDA's treatment of names and identifiers as data elements is closer to the FRBR attributes than to the FRAD concept of them as separate entities. For those interested in exploring subject analysis within the context of the FRBR conceptual model (including FRAD and FRSAD) and RDA, Zavalina explores the history of subject analysis and its lack of prominence within cataloging codes, and also explores the FRSAD concepts of "thema" and "nomen." ${ }^{\text {"1 }}$ For those interested in exploring authority control within the FRBR family, Doerr, Riva, and Žumer explain how conceptual models allow for the consistent use of identity, identification, and appellation that are crucial for authority control. ${ }^{22}$

Zhang and Salaba conducted three user studies for FRBRized catalogs. ${ }^{23}$ Users preferred the FRBR-based catalogs rather than regular catalogs due to their superior organization and faceted display, and were better able to accomplish their tasks, especially with known author or title searches. Morse describes how cartographic materials and sheet maps fit into the entity-relationship model of FRBR. ${ }^{24}$ Morse found that "the nontextual nature of sheet maps makes them difficult to fit into relationship taxonomies developed primarily for textual resources." ${ }^{, 25}$

One of the criticisms of FRBR is that it was developed fourteen years ago and that the library community is too late in adopting it. Rose points out that during that time, next generation catalogs have appeared and catalog design has moved away from FRBR, and so creating the FRBRized catalog now is a moot point.$^{26}$ Allison-Cassin offers an intellectual critique of how bibliographic data are organized in RDA and its underlying conceptual foundation of FRBR. ${ }^{27}$ She argues that the FRBR model is complex, rigid, causes imbalance in defining certain relationships over others, and removes serendipity in finding library data. To make bibliographic data more accessible to outside web services and systems, she proposes a new model of cataloging using linked data. Additional limitations of FRBR as it relates to linked data are noted below.

\section{The Future of Bibliographic Data Recording Formats: BIBFRAME}

The probable move away from MARC as the main data recording format for resource description invites commentary within the literature. MARC is not seen as compatible with the Semantic Web. Lee and Jacob, in an exploration of an alternative data format for holding bibliographic information, note that "MARC's ability to represent relationships between bibliographic entities with multilayered characteristics also is problematic because of its linearity and its flat, single-layered structure." ${ }^{28}$ They present an alternative approach to bibliographic data, creating a conceptual structure to identify core bibliographic elements and connect MARC elements to their related FRBR attributes and viceversa. Whereas their proposed structure is conceptual, not 
syntactic, the ideas are a step toward introducing relationships in catalogs.

During the period of this literature review, LC began research into developing a replacement for MARC and contracted with Zepheira to launch the Bibliographic Framework (BIBFRAME) Transition Initiative. ${ }^{29}$ Within ALA, the Library and Information Technology Association (LITA) and the Association for Library Collections and Technical Services (ALCTS), with the support of the Reference and Users Services Association (RUSA), formed the ALCTS/LITA Metadata Standards Committee, which began work during the ALA Midwinter meeting in January 2013 to consider new metadata. ${ }^{30}$ While the new committee could consider voting on issues related to MARC, MARC is not expected to be the its prevailing focus.

In early 2012, LC released a report on BIBFRAME. ${ }^{31}$ The report provides details about four BIBFRAME classes: Creative Work, Instance, Authority, and Annotation. It is designed to represent the relationships between entities as outlined in FRBR, and is presented in an RDF serialization to be compatible with linked data. Ford, recognizing both the virtues of a new format and the need to manage MARC legacy data, states, "Transition away from MARC will not be revolutionary, but a gradual process that ensures data integrity, system stability, and that no group is unintentionally left behind, in so far as is manageable." ${ }^{, 32}$

\section{Linked Data and Bibliographic Data Standards}

Although the concept of linked data has existed since Berners-Lee coined the term "Semantic Web" in 2001, it has grown in importance to both the library community and the greater web world. For readers new to the concept, one of the most comprehensive introductions and foundational readings on the subject is Coyle's review and description of linked data and Semantic Web standards in Library Technology Reports, "Linked Data Tools: Connecting on the Web."33 It is dedicated to explaining linked data, and provides an excellent starting point for understanding both what linked data are and their potential transformative power. Another excellent foundational article for understanding linked data and their potential for libraries is Schreur's "The Academy Unbound." 34 The current system of a master record in MARC format residing in a shared utility while individual libraries maintain their own copies is duplicative and inefficient, and MARC format does not interface well with the web environment. Pieces of a catalog record, though they make sense within the context of that record, have little meaning outside of the record, unlike a triple, which is self-contained. Catalogers need to let go of the concept of a bibliographic record and instead consider the individual triple statements that together make up a description of a resource, which Schreur labels a paradigm shift.

There is a growing body of literature that provides concrete examples of projects and prototypes using linked data. LOD projects of the British Library, Deutsche Nationalbibliothek, and OCLC, plus work-to-expression standards, including RDA and FRBR, in linked data terms are described in LC's paper introducing BIBFRAME. ${ }^{35}$ The W3C's Library Linked Data Incubator Group presented recommendations for libraries to become more involved in linked data projects by identifying data sets that can be exposed as linked data, increasing library participation in Semantic Web standards development, creating URIs and policies for managing linked data vocabularies and URIs, and providing libraries the experience to curate and preserve linked data sets over the long term. ${ }^{36}$ The Library Linked Data Workshop, held at Stanford University in 2011, sought to address the recommendations of the incubator group by building understanding and enthusiasm for linked data in libraries and presenting a value statement in support of linked data, with a list of potential linked data projects for libraries. $^{37}$

The Oslo Public Library's Pode Project highlights how library catalog data can be transformed into linked data ${ }^{38} \mathrm{It}$ uses an automated tool to FRBRize the display of MARC catalog records and uses linked data to connect to external sources of information such as DBpedia, Project Gutenberg, and the Virtual International Authority File (VIAF). Information Standards Quarterly featured a themed issue on linked data that cited many prominent linked data projects, including OCLC's use of schema.org to expose WorldCat to search engines. ${ }^{39}$ The Europeana Linked Data Pilot uses the Europeana Data Model to allow institutions to contribute their data in a linked data format. ${ }^{40}$ The Linked Open Copac and Archives Hub project of JISC uses linked data to connect biographical information to archival resources. ${ }^{41}$ In one of the more practical articles for helping institutions take the first step toward linked data, Van Hooland, Verborgh, and Van de Walle describe how to use Open Refine as a tool to clean up messy and inconsistent data before transforming them into linked data. ${ }^{42}$

For a comprehensive description of the entire FRBR family's (FRBR, FRAD, FRSAD) representation in linked data, readers would be best served to study Dunsire's paper "Representing the FR Family in the Semantic Web," which describes the development of the FRBR namespace. ${ }^{43}$ Baker critiques how the hierarchical structure within the FRBR Group 1 entities has been expressed in RDF using the Web Ontology Language (OWL) in such a way that there are four differentiated, non-overlapping entities. ${ }^{44}$ Thus a triple can belong to only one of the four Group 1 entities, so a resource, for example, cannot be declared both a work and an expression. Murray and Tillett, in their paper, "Cataloging 
Theory in Search of Graph Theory and Other Ivory Towers," consider how resource description is inherently limited by catalogers' viewpoints and biases, and suggest using graph theory from mathematics to consider multiple viewpoints and descriptions and link them together. ${ }^{45}$ They consider a reworking of FRBR's representation in RDF, and rather than strict demarcation between the FRBR Group 1 entities, they recommend that the system of description recommended by FRBR be considered as interrelated building blocks describing the characteristics and relationships among the entities.

Both Howarth and LeBoeuf believe that FRBRoo, as an object-oriented model, will be better positioned than the traditional entity-relationship in FRBR to be exposed using RDF technologies. ${ }^{46}$ Miller expressed concerns about using $\mathrm{RDF}$ as the data format for BIBFRAME and RDA data, and feels that like MARC, it is too complex and cumbersome to be adopted by the wider technology community beyond libraries; and the simpler schema.org, launched by Bing, Google, and Yahoo, would better serve libraries. ${ }^{47}$ Yee expresses concern regarding the decomposition of records into triples, stating, "RDA seems to take it on faith that a huge increase in granularity is a good thing without any prior experimentation to demonstrate how these tinier and tinier bits of data will be reassembled into coherent displays and indexes." 48

\section{Controlled Vocabularies and Authority Control}

Controlled vocabularies and authority control were popular topics in 2011 and 2012. Contributions in this area include the relationship of controlled vocabularies to the Semantic Web; projects to represent and improve the use of controlled vocabulary for retrieval; citations that focus on LCSH; usercontributed tags, including comparisons between them and traditional controlled vocabularies; and research related to name authority control.

The literature also addressed the creation of ontologies and the representation of controlled vocabularies in linked data. Coyle introduces many controlled vocabularies that are being made available in linked data format. ${ }^{49}$ Allinson describes how the Tate Museum developed its own ontology as part of creating the linked data set in the OpenART project. ${ }^{50}$ Nisheva-Pavlova and Pavlov provide another example with the description of subject ontology for access to a repository of Bulgarian folk songs. ${ }^{51}$ Pattuelli describes a project to develop an ontology for a digital primary source collection, "Tobacco Bag Stringing," at the University of North Carolina at Chapel Hill, where instructors planning to use the material provided input into ontology creation and revision. ${ }^{52}$

There are tools available to find information about different vocabulary projects that can help determine when an existing vocabulary will meet a project's need or if a new vocabulary is necessary. Hlava describes TaxoBank, a collaborative site where users can search for and add information on controlled vocabularies of all types. ${ }^{53}$ Another registry is the Open Metadata Registry (OMR), which grew out of the National Science Digital Library (NSDL) Registry. ${ }^{54}$ Dunsire et al. believe that while there are challenges in reusing other metadata and in trying to align new metadata with existing vocabularies, this type of mapping and alignment will best serve the Semantic Web in the future. ${ }^{55}$

As a popular controlled vocabulary for subject terms, LCSH was frequently discussed in the literature. For a basic introduction, Broughton's book, Essential Library of Congress Subject Headings, provides an overview of LCSH and is geared toward UK catalogers who might be unfamiliar with the controlled vocabulary. ${ }^{56}$ Several articles explore dissatisfaction over LCSH's coverage of terms used to describe certain populations. Essays by Greenblatt and Roberto complain that Lesbian, Gay, Bisexual, Transgender, Intersex, and Queer (LGBTIQ) populations are marginalized or misrepresented in $\mathrm{LCSH}^{57}$ In a survey distributed at five indigenous-related conferences and events in the US and Canada, respondents indicated dissatisfaction with current terminology in LSCH used to describe Native Americans, particularly in Canada. ${ }^{58}$

Strader examined the citation practices of 285 theses and dissertations at The Ohio State University (OSU) to compare citation patterns across disciplines and determine the effectiveness of LCSH in providing access across different meterial types. ${ }^{59}$ The study revealed that LCSH is less effective in providing subject access to those material types that present new research such as proceedings and presentations, thus suggesting that LCSH, by relying on catalogers' proposals of new headings through literary warrant, lags behind.

User-contributed metadata to enhance access to resources was discussed frequently within the 2011-12 literature. Terms supplied by users can create a system of related terms and categories, sometimes called a folksonomy. Porter provides an overview of folksonomies and reviews the related literature through $2009 .{ }^{60}$ Their main disadvantages, lack of semantic and linguistic control, are also their greatest strengths as they are not tied to particular terms, unlike traditional controlled vocabularies. Comparisons between usercontributed metadata and controlled vocabulary systems, particularly LCSH, frequently refer back to criticisms of traditional controlled vocabulary as too rigid and unable to represent the diversity of the users they are trying to serve. Alemu, Stevens, and Ross argue that "a social constructivist approach should be adopted by libraries and other cultural heritage institutions" and that collaborative metadata approaches, where users contribute metadata and there are terms assigned from a controlled vocabulary, will enhance 
interoperability by allowing for the representation of multiple viewpoints. ${ }^{61}$ As an example of the social constructivist approach, the Center for Colorado and the West at Auraria Library worked with members of Native American tribes and the Latino community to provide enhanced descriptions of digitized materials. ${ }^{62}$ Other articles by Anfinnsen, Ghinea, and de Cesare, Lee and Schleyer, and Stvilia, Jörgensen, and Wu explore how user-generated tags and folksonomies can complement, but not replace, controlled vocabularies. ${ }^{63}$

LibraryThing for Libraries (LTFL) provides a corpus of social tags to incorporate into library catalogs. DeZelarTiedman compared the University of Minnesota's catalog of LCSH coverage of literary works and LibraryThing's tag clouds to evaluate the benefit of LTFL ${ }^{64}$ She suggests the service might benefit most a subset of a library's catalog, like popular fiction, but also questions if the cost is worthwhile, given that so many searches start outside of the library cata$\log$. Through usability testing, Pirmann notes that LTFL tags show promise for enhancing subject access and discovery of items in the library catalog, but also notes some of their limitations, including the lack of system support for tagbased searches, lack of controlled vocabulary structures, and questionable relevancy of some tags. ${ }^{65}$

A major area of research has been exploring the use of identifiers to disambiguate names. For those unfamiliar with VIAF, Loesch provides an introduction that describes its creation and its contributing partners, including the Program for Cooperative Cataloging's (PCC) Name Authority Cooperative (NACO), Die Deutsche Bibliothek (German National Library), and the Bibliothèquenationale de France. ${ }^{66}$ The International Standard Name Identifier (ISNI), an ISO standard, uses VIAF data, along with industry data, to create what Nuttall and Oh describe as a "party identifier," which is a rigorous number designed to identify parties responsible for content, both for discovery purposes and for tracking royalties ${ }^{67}$ ISNI allows information to be shared across different domains without revealing sensitive information and, by using a unique identifying number, allows information to be used in linked data applications and to be identified as FRBR Group 2 entities.

Thomas believes that currently, information in authority records displayed to users in the catalog does not provide enough assistance to users to allow them to correctly identify a person. ${ }^{68}$ He examines how different web resources, such as the Internet Movie Database (IMDB) and Wikipedia disambiguate names, and suggests that libraries add short descriptive phrases to authority records. Bainbridge, Twidale, and Nichols offer a method for user feedback to improve authority control and assist in name disambiguation. ${ }^{69}$ They created a prototype that allows users to confirm or deny potential authority matches, and enables the system to use this feedback to update authority records.

\section{Classification}

The literature published in 2011-12 highlights classification practices of libraries using both standard and custom classification systems. DDC is in its 135th year of publication and its 23rd edition was published in 2011. The 23rd edition is available online as WebDewey, and incorporates the abridged DDC 15th edition. ${ }^{70}$ This edition introduces minor changes in terminology, adds more languages in table 6 , and relocates numbers within a few classes. ${ }^{71}$ Trickey provides an overview of the full 23rd edition of DDC. ${ }^{72} \mathrm{~A}$ series of new topics such as cloud computing, bullying, and Pilates have been added, and the recent edition has increased subject specificity. Using a randomly selected sample of 100 DDC classes, Green studied see-also relationships within DDC that are intended to help catalogers distinguish and select the relevant class, and suggests steps to improve the use of these relationships. ${ }^{73}$

Lösch et al. created a bilingual text corpus using DC metadata collected through the Open Archives Initiative Protocol for Metadata Harvesting (OAI-PMH) and aggregated for the Bielefeld Academic Search Engine (BASE). ${ }^{74}$ Each record is annotated with at least one DDC classification number that provides subject mapping of the corpus. Joorabchi and Mahdi propose a prototype software system for automatic classification of scientific documents according to DDC. ${ }^{75}$ The authors applied DDC to references in research articles, papers, and reports from CiteSeer, a scientific digital repository.

For readers interested in LCC, Higgins offers a historical account of LCC's development and its relationship to $\mathrm{LCSH}^{76}$ Although LCC is often used in large academic libraries, it reflects "a superannuated American viewpoint" and "systemic problems inherited from the scheme's founding principles." inherent quirks and problems, and argues that it fails to meet the needs of the twenty-first century.

Class N or Fine Arts in the LCC is the schedule used the most by fine art libraries. Clarke delves into the history, organization, new editions, and current structure of the Class N schedule, noting some challenges specialized libraries may have, particularly in relation to country of origin and photography. ${ }^{78}$ Lee illustrates an example of customizing the $\mathrm{N}$ schedule for art libraries by describing the Courtauld Classification System (CCS), used at the Courtauld Institute and adapted from the third edition of the LCC's N schedule. ${ }^{79}$ Customization allows it to fit the library's collection, but entails a continuing commitment for the library to stay current with modifications to ensure that it reflects the library's collection and new forms of resources.

Other forms of classification were covered in the literature, including Colon Classification (CC), a faceted classification system developed by Ranganathan and used in 
Indian libraries. Bianchini analyzed how FRBR entities can be mapped to call numbers in CC. ${ }^{80}$ He illustrates how the different units that compose a full CC call number can be mapped to different attributes within the FRBR family. The Tate Library uses Universal Decimal Classification (UDC) to classify its art materials, with an in-house extension to UDC developed to accommodate materials published in 20th-century art. ${ }^{81}$ Mages presents the history and inspiration behind the construction of the Bellevue Classification System (BCS), created by nursing instructor Ann Doyle during the 1930s for use in the Bellevue School of Nursing Library. ${ }^{82}$ The BCS allowed Doyle to represent topics closely related to nursing and to "portray nursing as an intellectual and professional discipline." ${ }^{.33}$

\section{Bibliographic Control}

The literature was replete with material the authors have grouped under the broad rubric of "Bibliographic Control." This section contains analyses, case studies, thought pieces, pedagogical material, and experiments that relate to the theory and practice of library cataloging and bibliographic control. The diverse topics under this heading are further grouped into the following subheadings: Evaluation and History of Cataloging, Special Formats Cataloging, Discovery Services, Cataloging beyond RDA/AACR2 and MARC, and Workflows and Cooperative Cataloging.

\section{Evaluation and History of Cataloging}

"Assessing the Cost and Value of Bibliographic Control," a paper by Cronin and Stalberg, grew out of the 2009 Association for Library Collections and Technical Services Heads of Technical Services in Large Research Libraries Interest Group Task Force on Cost/Value Assessment of Bibliographic Control. ${ }^{84}$ The task force was charged to explore the cost and value of bibliographic control, driven by recommendation 5.1.1.1 of On the Record: Report of the Library of Congress Working Group on the Future of Bibliographic Control, which focused on developing measures for costs, benefits, and value of bibliographic control. ${ }^{85}$ Because definitions for the value of bibliographic control were largely missing, the task force chose to define seven operational definitions of value and provided recommendations for a research agenda and strategies for advancing that research.

The articles on the history of cataloging provide background and context to current standards, data formats, and cataloging practice, and frequently speculate on how past practice and ideas can help shape the future. Genetasio explores the genesis of the Statement of International Cataloguing Principles (ICP), published in February 2009 ${ }^{86}$ The ICP broadens the scope of the earlier Paris Principles to include all types of materials and all aspects of bibliographic and authority data, along with references to ISBD, FRBR, and FRAD. Genetasio criticizes the ICP for its lack of an overall theoretical vision, specificity in bibliographic description, subject cataloging, and general vagueness about the convenience of users.

Seikel and Steele take the reader on a historical journey of MARC starting with the development of MARC I in 1965 and concluding with MARC 21 in the late 1990s. ${ }^{87}$ The article provides a thorough discussion of how MARC 21 will change with the adoption of RDA, including what new fields and tags will be added to MARC 21 bibliographic and authority formats.

In "The Legacy of the Library Catalogue for the Present," Miksa elucidates the evolution of the catalog from the middle of the 19th century to the present by discussing four historical themes related to the library catalog to measure its legacy: the dictionary catalog, catalog users and use, developments occurring outside of the library catalog world, and the idea of the objects of the library catalog. ${ }^{88}$ He traces evolution of the environment for the twenty-first century catalog to explore how change in the catalog may guide the development of present and future library catalogs.

\section{Special Formats Cataloging}

Contributions to the literature focusing on issues of cataloging and bibliographic control often revolved around issues related to the type of item or format being cataloged. Representative articles in this section include non-Roman scripts, music materials, and Electronic Theses and Dissertations (ETDs). Biella and Lerner examined how RDA would affect the cataloging of Hebraica. ${ }^{89}$ Their article details the various challenges encountered during the RDA testing period, including determining appropriate dates, recording the statement of responsibility, and Romanization issues. Kudo details problems in the transliteration of Japanese characters due to conflicting policies regarding the Modified Hepburn Romanization system, which result in inconsistencies in the recording of specific sounds and syllables. ${ }^{90}$ Cataloging works in Romani, a language lacking a governmentally sanctioned "official orthography," presents a series of distinct challenges, described by Husic, who provides suggestions for transcribing characters that are not part of the Unicode subset used in WorldCat. ${ }^{91}$

Directions in Music Cataloging, a Festschrift to honor music cataloger Arsen Ralph Papakhian, covers a wide range of issues related to music cataloging, including a history of the Music OCLC User group, the LC Genre/Form Terms for Library and Archival Materials (LCGFT), cataloging music on iTunes, consideration of how RDA and FRBR will change cataloging practices, and cataloging practices related to ethnographic field recordings. ${ }^{92}$ Thornburg and Oskins 
examine the use of Global Library Manifestation Identifier (GLIMIR) identification numbers in the OCLC Extended WorldCat set to collocate records on music materials. ${ }^{93}$ Riley describes Variations/FRBR, an IMLS grant-funded project at Indiana University, and covers lessons learned in implementing the FRBR conceptual model for existing data in a music digital library and the work done to identify FRBR Works from MARC and roles for FRBR Group 2 entities as part of the FRBRization process. ${ }^{94}$ A special issue of Fontes Artes Musicae was devoted to music cataloging and RDA. ${ }^{95}$ Harden outlines the development of RDA, FRBR, genre/ form and medium terms to be used as "subjects," and a possible development of a new encoding standard to replace MARC. ${ }^{96}$ Cato's article outlines different cataloging practices in various European countries, how they might change if RDA is adopted, and how IFLA may help in shaping various cataloging practices ${ }^{97} \mathrm{McKnight}$ describes the work of the LC Music Genre/Form Project Group to create a thesaurus of genre and form terms to develop a prototype thesaurus. ${ }^{98}$

Maurer, McCutcheon, and Schwing describe Kent State University Library's ETD cataloging process that combines contributions from authors, catalogers and a systems application. ${ }^{99}$ The researchers found that "authors can supply accurate and findable metadata, that the ETDcat application can transmit and manipulate that metadata in ways that improve findability, and that catalogers' contributions improve findability." 100 In a similar exploration of workflow and record enhancement, Howard and Goldberg detail how they transformed metadata from the simpler DC to the more granular MARC using the WorldCat Digital Collection Gateway. ${ }^{101}$

\section{Discovery Services}

In recent years, the library community has focused attention on "next-generation" catalogs (NGCs) and web-scale discovery tools. Both are designed to help library catalogs break away from traditional OPACs by incorporating more search features, providing interface enhancements, and, particularly for web-scale tools, bringing article content together with traditional library catalog data for a single unified search index. This review includes articles on the intersection of discovery services and bibliographic control, with topics covering theoretical considerations, implementation decisions, and user studies. A theoretical article by SchultzJones et al. considers how the quality of cataloging choices and cataloger judgment will affect NGCs. ${ }^{102}$ The authors synthesize studies that highlight quality of cataloging in the past few years and pose the question that if catalogers did not use resources or tools to make good cataloging decisions, then "what assurance is there that they will understand how an NGC provides the user with more layers of discovery based on the data already present in the system?" ${ }^{p 103}$ Barton and Mak consider the prospect of NGCs and the consolidation of access to all library collections through a single search box. ${ }^{104}$ While the authors are hopeful that the ideal next generation catalogs will weave silos of information together with enhanced navigation and usability in one portal for access, they wonder how libraries will manage the vast amounts of metadata from diverse sources, and how RDA/FRBR implementation of catalogs will be affected by the influx of external data.

Case studies of discovery service implementation were common. Han describes the implementation and integration of VuFind and Easy Search at the University of Illinois at Urbana-Champaign, Graves and Dresselhaus detail work done at the Old Dominion University Library to implement WorldCat Local, and Daniels and Roth share their experiences of implementing Summon at Grand Valley State University in 2009. ${ }^{105}$ These articles detail the steps taken at each library during the migration, including clean-up work, MARC-mapping processes, and ensuring accurate representation of library holdings in the services.

The single search box option to search a broad range of library materials and ease of use offered by discovery tools has revolutionized the end user's search and discovery experience, but unexpectedly changed cataloging functions. Surveying and interviewing libraries implementing NGCs, Wynne and Hanscom determined that catalogers were actively involved in the implementation process and in data maintenance and clean-up activities, and worked with vendors to correct data. ${ }^{106}$ This allowed catalogers to become active participants to improve access, collaborate with other units, and to demonstrate their value to the community. Harpel-Burke's article reports on the results of a survey of academic libraries that implemented discovery systems, both NCG and web-scale. ${ }^{107}$ The respondents were split in opinion on whether discovery systems exposed errors or suppressed OPAC data, indicating that libraries are unsure about the future of catalog maintenance and authority control activities while using discovery systems.

User studies on the effects of cataloging decisions, enhancements to data, and bibliographic control processes were also represented in the literature. Studies by Walsh, Denton and Coysh, and Skinner evaluated NGCs. ${ }^{108}$ Their findings report that although enhanced catalog records or NGCs offered better search experiences for users, they posed challenges in the discovery of known titles or items in a series or journal and displayed cataloging errors and problems in the legacy records. Bauer and Peterson-Hart did usability testing of two catalog interfaces for the use of subject headings in YuFind (faceted) and Orbis (non-faceted), running side-by-side at Yale University. ${ }^{109}$ Subject heading facets did not increase the use of subject headings as users discovered YuFind records in Google and followed the link to YuFind. The authors speculate that "the usefulness 
of YuFind may lie more in its ability to provide records to Google than its faceted navigation."110

\section{Metadata Beyond RDA/AACR2 and MARC}

Exploration of metadata in a library setting beyond "traditional" cataloging using AACR2/RDA and MARC occupies a substantial portion of the literature. The articles covered here relate exclusively to descriptive metadata. Readers looking for a practical guide to metadata beyond AACR2/ RDA and MARC will find Miller's book, Metadata for Digital Collections: A How-To-Do-lt Manual, to be an excellent place to start. ${ }^{111}$ It covers basic concepts like controlled vocabularies, resource description, and XML encoding, and provides in-depth coverage of three commonly used metadata schemes: DC, Metadata Object Description Schema (MODS), and Visual Resources Association (VRA) Core.

Workflow, metadata management, and transformation were frequent topics in the literature. Laursen, Christiansen, and Olsen describe the workflow for working with metadata for digital heritage collections developed at the State and University Library in Denmark. ${ }^{112}$ They recommend considering any available sources of metadata before choosing a scheme, and basing the workflow on the sources available. Both Martin, and Southwick and Lampert, note the utility of a data dictionary to clearly define metadata elements, provide guidelines and training for metadata creation. ${ }^{113}$ Walsh describes two projects at the OSU Library to create DC records for the university's institutional repository: OSU Press' open-access monographs and the oral history collections of the OSU Byrd Polar Research Center Archival Program. ${ }^{114}$ She describes the use of EXtensible Stylesheet Language Transformation (XSLT) to transform MARC into DC.

Several articles describe the work performed at different institutions to select standards and cleanup existing metadata. Guza applies Greene and Meissner's archival principle of "more product, less process" to encourage the appropriate balance between expediency and completeness in developing a metadata strategy for the digitization of the Century 21 Expositions Digital Collection at the Seattle Public Library. ${ }^{115}$ McBride describes the efforts at the University of North Carolina at Chapel Hill to clean up and standardize the metadata of an older digital sheet music collection. ${ }^{116}$ However, Brodsky, interviewed by Tobar, rejects the importance of mapping and sharing metadata for a large multimedia digital collection of scores, concert programs, and videos used by the New York Philharmonic. ${ }^{117}$ Brodsky states, "The metadata is very specific and well-structured, so we don't see the point in mapping it all to some other system that doesn't mean anything to us."

Reviews of metadata quality and consistency also appeared in the literature. Westbrook et al. describe an audit of DC metadata for digital collections in the University of Houston Digital Library, in which metadata were reviewed for completeness and inconsistencies to improve search and discovery. ${ }^{118}$ In a similar study, Lim and Liew examined images from sixteen institutions in New Zealand, reviewed metadata records and interviewed staff regarding their practices. ${ }^{119}$ They found that metadata was inconsistently applied across the organizations, hampering interoperability and cross-institutional access.

Some activities commonly described in metadata work-namely, transformation and harvesting-may no longer be necessary within a future of linked data and RDF. As Baker states, RDF provides "a linguistic basis for expressing and linking data ... RDF provides a common second language into which local data formats can be translated and exposed ... RDF triples do not require additional out-of-band information for their interpretation. In this sense, RDF data can be said to "speak for itself."'120 While DC is already described using RDF, exactly how RDF triples will interact with each other is yet to be determined. As with the switch to RDA and the investigation of a replacement for MARC, metadata beyond RDA and MARC are also in flux.

\section{Workflows and Cooperative Cataloging}

The literature on workflows related to technical services falls into various areas, including batch processing of records and migration to new systems, clean-up projects for existing resources, digital resources workflows, and workflows developed through cooperative cataloging. Libraries are increasingly using batch processes to load bibliographic records and provide access to large collections of materials. Mugridge and Edmunds report on a survey by the ALCTS Directors of Large Research Libraries Interest Group that gauges how members managed batchloading activities. ${ }^{121}$ The responses detail the staffing, management processes, and frustrations over current workflows for getting the records into the cata$\log$, and point out challenges, such as poor record quality or library systems that cannot manage the volume of records. Young performed a survey of batchloading practices that included a wider range of respondents from three different email discussion lists, and found similar frustrations with the batchload process. ${ }^{122}$ Both surveys indicate that respondents believe that batchloading will increase in the future. Mugridge and Edmunds' article notes two areas for further research that may affect the future amount of batchloading: how discovery systems will impact the need to batchload records, and identifying the kinds of assessment necessary to ensure that batchloading has improved the discovery of library materials.

Collaborations among various departments within the library appear to be a trend in developing new workflows 
to offer better discovery experiences to users. The Special Collections Department and Access Services Unit at the University of North Carolina-Charlotte's J. Murrey Atkins Library undertook a project in which Access Services staff were trained to create DC descriptive metadata records for digital photographs, maps, and oral histories. ${ }^{123}$ Evans and Tilton describe how academic libraries can work with satellite units on campus to provide access to specialized collections without overwhelming existing cataloging staff. ${ }^{124}$ In their example, the University Libraries at Bowling Green State University, rather than attempting to incorporate the material directly into the catalog, provided their knowledge and expertise to the design of a separate lightweight system for a collection of VHS cassettes and DVDs for the Dr. Ralph H. Wolfe Viewing Center.

In recent years, the integration of non-MARC metadata into traditional cataloging workflows has gained momentum. The University of Montana cataloging department created metadata for a digital project, Natives of Montana Archival Project (NOMAP). ${ }^{125}$ Keenan discusses some of the problems of integrating metadata creation into the department, and notes that new skills such as "graphic design, data structure, and experience with relational databases are becoming just as important to potential catalogers as are attention to detail and an understanding of cataloging and indexing." 126

A catalog at the regional level can reduce redundancy in work, especially when a bibliographic record serves more than one library. Preston provides an account of workflows and challenges in a case study of cooperatively cataloging e-book collections by OhioLink libraries. ${ }^{127}$ Martin et al. present a case study of managing cataloging guidelines for e-resources for the Consortium of Academic and Research Libraries in Illinois (CARLI) shared catalog, I-Share. ${ }^{128}$ In the aptly named article, "10\% Wrong for $90 \%$ Done: A Practical Approach to Collection Deduping," Hamby discusses the challenge of identifying and merging duplicate records in a new open-source consortial integrated library system for the South Carolina Library Evergreen Network Delivery System (SC LENDS). ${ }^{129}$ The consortium developed an algorithm that matched bibliographic records 90 percent of the time. Other consortiums using the Evergreen ILS have been able to use and expand upon the same code developed by SC LENDS.

\section{Cataloging Education and Careers in Cataloging}

The role of catalogers and cataloging are in a state of flux with the introduction of a new cataloging code and cataloging syntax, although with long-term trends toward less catalogerspecific education and fewer cataloging positions in libraries. The debates over whether libraries need catalogers, the necessity of cataloging education, and the future of cataloging continue. Joseph Miller, interviewed by Marcus, stresses his belief that ALA should include a cataloging component as an accreditation requirement: "Not every librarian needs to know how to do original cataloging, but every librarian needs to know the basics of data structure, bibliographic description, and subject analysis." ${ }^{330}$ In the book, Conversations with Catalogers in the 21st Century, essays by Hill and Hall-Ellis underscore the importance of including cataloging in the broader context of information organization courses in LIS programs and suggest how education can be improved for catalogers. ${ }^{131}$ Hill reasons that lack of exposure, lack of required cataloging courses in LIS programs, and reliance upon adjuncts instead of full-time faculty to teach cataloging courses are some of the reasons why fewer students are drawn to cataloging. However, Hall-Ellis is optimistic about the offerings of LIS programs that include fundamental information organization as a core course, and specialized courses in description, classification, authority control, indexing, and thesaurus construction.

Technology has changed the method of LIS education from more didactic face-to-face education to online courses, webinars, and reading or writing blogs and wikis. Cataloging and Classification Quarterly published a special issue on "Online Delivery of Cataloging and Classification Education and Instruction" that explored how to deliver cataloging and classification instruction effectively in the online environment. ${ }^{132}$ Articles cover the range of developing appropriate curriculum, learning technologies, and methods for teaching online courses; assessment of course material; and online methods for on-the job-training. ${ }^{133}$

As technical services departments experience changes in functions and daily operations due to shrinking budgets the merging of acquisitions and cataloging departments, and increasing use of vendor records, support staff have started assuming more original cataloging responsibilities and are undergoing significant training. This is evident in Gelber and Kandarasheva's case study of how copy catalogers at Columbia University Library were trained in the Name Authority Cooperative Program (NACO) to catalog belles lettres materials, including the creation of the associated name headings and call numbers. ${ }^{134}$

Finally, there were essays on the future of the cataloging profession that are worth mentioning. Hoffman writes very thoughtfully on the future of cataloging using Abbott's theory of "The System of Professions," which considers how technology can create or destroy new work and compel competing professions to fight for the same work. ${ }^{135}$ Hoffman uses this theory to show how technology has created and destroyed cataloging work and believes that e-resources and metadata librarians compete with catalogers for new areas of professional work such as institutional repositories or electronic collections. Similarly, in "Is There a Future for 
Library Catalogers?" Cerbo implies that catalogers need to extend their professional cataloging skills to accommodate e-resources and digital initiatives to keep themselves relevant. $^{136}$

\section{Conclusion}

The cataloging and classification literature published in 2011-12 reveals that the cataloging community is preparing for a major shift, with a new cataloging code to be implemented, an impending new syntax for holding catalog data, and potentially a complete paradigm shift moving away from thinking about individual records to triples of information that can be linked together on the fly. The anxiety of the library community over the adoption and learning of RDA and its underlying model FRBR is apparent. The explosion of literature on RDA indicates that it is an area of utmost importance and relevance to the cataloging community as it prepares to embrace challenges of learning the new code and principles of FRBR, which will lead to significant changes in cataloging practices. LC's new proposed framework, BIBFRAME, begins the transition away from MARC, which libraries have used for more than forty years.

The application of the FRBR family of models, including FRAD and FRSAD, to unfold relationships between flat and linear bibliographic data, various FRBR exploration studies, and studies FRBRizing library catalogs demonstrates that libraries are continuing to explore and experiment with the conceptual model. The FRBR family has received criticism for being too hierarchical within the Group One entities, and too long in the making. A new object-oriented approach, FRBRoo, has been proposed, which some view as a better fit for linked data.

Linked data projects have allowed bibliographic data to move beyond the library catalog and to be more accessible to the wider web and through the Linked Open Data Cloud. Extensive education is needed regarding linked data and the Semantic Web, though the principles of linked data and the Linked Open Data movement have gained a firm foothold. European libraries have been actively testing projects and developing prototypes following a linked data model, but one would expect to see more reports on US projects in coming years. As Scheuer says, linked data will expand discoverability, and create a host of possibilities for libraries to reuse their data to improve services and reach their users in new locations: "a linked data environment has no bounds." 137

Controlled vocabularies and authority control continued to play a prominent role in the literature during the review period, and perhaps even have gained in stature as libraries consider how to open their data to the wider world. Identifiers and contextual information about authors have grown in importance, as libraries share authority data through global projects such as VIAF, and pursue linked data solutions. While user-contributed terms and tags are not seen as a replacement for controlled vocabularies, studies in the literature acknowledge the complementary role that user-contributed metadata can provide to improve resource discovery. The coming years should see improvements in library systems to better take advantage of both traditional controlled vocabularies and user-contributed metadata.

Evaluation of cataloging was a small area of research in the literature published during 2011-12. A seminal contribution by Cronin and Stalberg offers seven operational definitions of the value of bibliographic control to help institutions measure and justify its cost. In the future, more research into this area on how and whether people measure the value and cost of bibliographic control is eagerly anticipated.

The evolution of the library catalog over the last few decades from card catalogs to OPACS to NGCs to web scale discovery services is evident in the literature. The library community appreciates the enhancements to the user discovery experience while at the same time grapples with the problems of diverse metadata and missing content. The impact of discovery systems on the need to batchload records for e-resources in the catalog will invite discussion at individual institutions. Finally, an upcoming trend is increased collaboration among various departments within the library to improve and develop new workflows both to gain efficiencies and to improve discovery.

Cataloging education and careers remains a wellrepresented subject in the literature. With the shifts in the catalog code and a movement toward linked data, the education of future catalogers and even what exactly a future cataloger will be, are likely to remain topics of genuine interest. As external data from library systems beyond the catalog and from vendor sources are incorporated into discovery systems and transformed into linked data, catalogers' work and responsibilities have the potential to broaden. The future of cataloging remains uncertain, but these changes can also present an enormous opportunity. As Hoffman says, "Cataloging has the power to secure a place in the functional future; catalogers just need to claim the work." ${ }^{338}$

\section{References}

1. United States RDA Test Coordinating Committee, Report and Recommendations of the U.S. RDA Test Coordinating Committee (May 2011, revised for public release June 20, 2011), accessed May 9, 2014, www.loc.gov/bibliographic -future/rda/source/rdatesting-finalreport-20june2011.pdf.

2. Library of Congress, Testing Resource Description and Access: U.S. National Libraries RDA Test Partners, accessed May 9, 2014, www.loc.gov/bibliographic-future/rda/about.html.

3. United States RDA Test Coordinating Committee, Report and Recommendations.

4. Sylvia D. Hall-Ellis and Robert O. Ellett, "Introduction," Cataloging \& Classification Quarterly 49, no. 7-8 (September 
2011): 567-71, dx.doi.org/10.1080/01639374.2011.618377.

5. Judith A. Kuhagen, "Training for the U.S. RDA Test," Cataloging \& Classification Quarterly 49, no. 7-8 (September 2011): 572-81, dx.doi.org/10.1080/01639374.2011.616924.

6. Christopher Cronin, "From Testing to Implementation: Managing Full-Scale RDA Adoption at the University of Chicago," Cataloging \& Classification Quarterly 49, no. 7-8 (September 2011): 626-46, dx.doi.org/10.1080/01639374.2011.616263.

7. Jennifer B. Young and Valerie Bross, "Results of the CRCC Informal RDA Testing Task Force," Cataloging \& Classification Quarterly 49, no. 7-8 (September 2011): 600-606, dx.doi.org/10.1080/01639374.2011.620223; Marjorie E. Bloss, “Testing RDA at Dominican University's Graduate School of Library and Information Science: The Students' Perspectives," Cataloging \& Classification Quarterly 49, no. 7-8 (September 2011): 582-99, dx.doi.org/10.1080/01639374.2011.616 264; Kathryn La Barre et al., "Perspectives from the University of Illinois at Urbana-Champaign; Participants in the U.S. National Libraries RDA Test," Cataloging o Classification Quarterly 49, no. 3 (2011): 243-53.

8. Megan Kettner, "RDA Toolkit," Theological Librarianship 4, no. 1 (2011): 105-6, accessed May 9, 2014, journal.atla.com/ ojs/index.php/theolib/article/view/175/464; Megan Curran, "RDA Toolkit - http://access.rdatoolkit.org/," Technical Services Quarterly 28, no. 2 (February 28, 2011): 251-52, dx.doi .org/10.1080/07317131.2011.546301.

9. Bloss, "Testing RDA at Dominican University's Graduate School"; La Barre et al., "Perspectives from the University of Illinois at Urbana-Champaign.”

10. Peggy Johnson, "From the Editor's Desk," Technicalities 32, no. 1 (2012): 2-3.

11. Kevin M Randall, "RDA: End of the World Postponed?," Serials Librarian 61, no. 3-4 (2011): 334-45, dx.doi.org/10.1080/0 361526X.2011.617297.

12. Barbara B Tillett, "Keeping Libraries Relevant in the Semantic Web with Resource Description and Access (RDA)," Serials: The Journal for the Serials Community 24, no. 3 (2011): 266-72, dx.doi.org/10.1629/24266.

13. Anne Welsh and Sue Batley, Practical Cataloguing: AACR, RDA and MARC21 (Chicago: Neal-Schuman, 2012); Mary Beth Weber and Fay Angela Austin, Describing Electronic, Digital, and Other Media Using AACR2 and RDA : A HowTo-Do-It Manual and CD-ROM for Librarians (New York: Neal-Schuman Publishers, 2011).

14. Sevim McCutcheon, "Designing Policy for Copy Cataloging in RDA," Library Collections, Acquisitions, and Technical Services 36, no. 3-4 (2012): 69-78, dx.doi.org/S1464905512000255.

15. Cataloging \& Classification Quarterly 50, no. 5-7 (special issue, 2012), accessed May 15, 2014, www.tandfonline.com/ toc/wecq20/50/5-7\#.U3UFQBC04II.

16. Richard P. Smiraglia, "Be Careful What You Wish For: FRBR, Some Lacunae, A Review," Cataloging \& Classification Quarterly 50, no. 5-7 (June 2012): 360-68, dx.doi.org/10.1080/016 39374.2012 .682254 .
17. Patrick Le Boeuf, "Foreword," Cataloging \& Classification Quarterly 50, no. 5-7 (June 2012): 355-59, dx.doi.org/10.1080 /01639374.2012.682001.

18. Patrick Le Boeuf, “A Strange Model Named FRBRoo," Cataloging \& Classification Quarterly 50, no. 5-7 (June 2012): 422-38, dx.doi.org/10.1080/01639374.2012.679222.

19. Shoichi Taniguchi, "Viewing RDA from FRBR and FRAD: Does RDA Represent a Different Conceptual Model?," Cataloging \& Classification Quarterly 50, no. 8 (November 2012): 929-43, dx.doi.org/10.1080/01639374.2012.712631.

20. Pat Riva and Chris Oliver, "Evaluation of RDA as an Implementation of FRBR and FRAD," Cataloging b Classification Quarterly 50, no. 5-7 (2012): 564-86, dx.doi.org/10.1080/016 39374.2012 .680848$.

21. Oksana L. Zavalina, "Subject Access: Conceptual Models, Functional Requirements, and Empirical Data," Journal of Library Metadata 12, no. 2-3 (2012): 140-63, dx.doi.org/10.1 080/19386389.2012.699829.

22. Martin Doerr, Pat Riva, and Maja Žumer, "FRBR Entities: Identity and Identification," Cataloging \& Classification Quarterly 50, no. 5-7 (2012): 517-41, dx.doi.org/10.1080/016 39374.2012 .681252 .

23. Yin Zhang and Athena Salaba, "What Do Users Tell Us about FRBR-Based Catalogs?," Cataloging \& Classification Quarterly 50, no. 5-7 (2012): 705-23, dx.doi.org/10.1080/0163937 4.2012.682000.

24. Tami Morse, "Mapping Relationships: Examining Bibliographic Relationships in Sheet Maps from Tillett to RDA," Cataloging \& Classification Quarterly 50, no. 4 (2012): 22548, dx.doi.org/10.1080/01639374.2012.657292.

25. Ibid., 245.

26. Mary Z. Rose, “The Ship Has Sailed and We Aren't On It: How Catalogers Could Support User Tasks and Why We Won't, Journal of Library Metadata 12, no. 2-3 (2012): 12739, dx.doi.org/10.1080/19386389.2012.699828.

27. Stacy Allison-Cassin, "The Possibility of the Infinite Library: Exploring the Conceptual Boundaries of Works and Texts of Bibliographic Description," Journal of Library Metadata 12, no. 2-3 (2012): 294-309, dx.doi.org/10.1080/19386389.2012 .700606 .

28. Seungmin Lee and Efin K Jacob, “An Integrated Approach to Metadata Interoperability Construction of a Conceptual Structure between MARC and FRBR," Library Resources \& Technical Services 55, no. 1 (2011): 17-32, dx.doi .org/10.5860/lrts.55n1.17.

29. Matt Enis, "LC Announces Linked Data Modeling Initiative," Library Journal 137, no. 11 (2012): 20.

30. Cynthia Hodgson, "MARBI Disbanded; New ALCTS/LITA Metadata Standards Committee Formed," Information Standards Quarterly 24, no. 2/3 (2012): 53, dx.doi.org/10.3789/ isqv24n2-3.2012.11.

31. Library of Congress, Bibliographic Framework as a Web of Data: Linked Data Model and Supporting Services (Washington, DC: Library of Congress, 2012), accessed May 10, 2014, 
www.loc.gov/bibframe/pdf/marcld-report-11-21-2012.pdf.

32. Kevin Ford, "LC's Bibliographic Framework Initiative and the Attractiveness of Linked Data," Information Standards Quarterly 24, no. 2/3 (2012): 48, dx.doi.org/10.3789/ isqv24n2-3.2012.09.

33. Karen Coyle, "Metadata Elements," Library Technology Reports 48, no. 4 (2012): 15-26, dx.doi.org/10.5860/ltr.48n4.

34. Philip Evan Schreur, "The Academy Unbound," Library Resources \& Technical Services 56, no. 4 (2012): 227-37, dx.doi.org/10.5860//rts.56n4.227.

35. Library of Congress, "Bibliographic Framework as a Web of Data."

36. "W3C Library Linked Data Incubator Group Issues Final Report," Information Standards Quarterly 23, no. 4 (2011): 28, dx.doi.org/10.3789/isqv23n4.2011.08.

37. Michael A. Keller et al., Be Part of the Web, Not Just On It: Report of the Stanford Linked Data Workshop, 27 June-1 July 2011 (Stanford, 2011), accessed May 10, 2014, lib.stanford .edu/files/Stanford_Linked_Data_Workshop_Report_FINAL .pdf.

38. Anne-Lena Westrum, Asgeir Rekkavik, and Magnus Enger, "The Key to the Future of the Library Catalog Is Openness," Computers in Libraries 31, no. 3 (2011): 10-14; Anne-Lena Westrum, Asgeir Rekkavik, and Kim Talleras, "Improving the Presentation of Library Data Using FRBR and Linked Data," Code4Lib Journal, no. 16 (2012): 1-7, accessed May 10, journal.code4lib.org/articles/6424.

39. Ted Fons, Jeff Penka, and Richard Wallis, "OCLC's Linked Data Initiative: Using Schema.org to Make Library Data Relevant on the Web," Information Standards Quarterly 24, no. 2/3 (January 2012): 29, dx.doi.org/10.3789/isqv24n2-3.2012.05.

40. Antoine Isaac, Robina Clayphan, and Bernhard Haslhofer, "Europeana: Moving to Linked Open Data," Information Standards Quarterly 24, no. 2/3 (January 2012): 34, accessed May 10, 2014, www.niso.org/publications/isq/2012/v24no2-3/ isaac.

41. Jane Stevenson, "Linking Lives: Creating An End-User Interface Using Linked Data," Information Standards Quarterly 24, no. 2/3 (January 2012): 14-23, dx.doi.org/10.3789/ isqv24n2-3.2012.03.

42. Seth Van Hooland, Ruben Verborgh, and Rik Van de Walle, "Joining the Linked Data Cloud in a Cost-Effective Manner," Information Standards Quarterly 24, no. 2/3 (January 2012): 24-28, dx.doi.org/10.3789/isqv24n2-3.2012.04.

43. Gordon Dunsire, "Representing the FR Family in the Semantic Web," Cataloging \& Classification Quarterly 50, no. 5-7 (June 2012): 724-41, dx.doi.org/10.1080/01639374 .2012 .679881 .

44. Thomas Baker, "Libraries, Languages of Description, and Linked Data: A Dublin Core Perspective," Library Hi Tech 30, no. 1 (2012): 116-33, dx.doi.org/10.1108/07378831211213256.

45. Ronald J. Murray and Barbara B. Tillett, "Cataloging Theory in Search of Graph Theory and Other Ivory Towers," Information Technology \& Libraries 30, no. 4 (2011): 17084, acessed May 10, 2014, ejournals.bc.edu/ojs/index.php/ital/ article/view/1868.

46. Lynne C. Howarth, "FRBR and Linked Data: Connecting FRBR and Linked Data," Cataloging \& Classification Quarterly 50, no. 5-7 (2012): 763-76, dx.doi.org/10.1080/01639374 .2012.680835; Le Boeuf, "A Strange Model Named FRBRoo."

47. Dick R. Miller, "Identities and Relationships: Parallels Between Metadata and Professional Relevance," Journal of the Medical Library Association 100, no. 2 (2012): 83-86, dx.doi.org/10.3163/1536-5050.100.2.003.

48. Martha Yee, "The Single Shared Catalog Revisited," in Conversations with Catalogers in the 21st Century, ed. Elaine R. Sanchez (Santa Barbara California: Libraries Unlimited, 2011), 129.

49. Karen Coyle, "Vocabularies: Term Lists and Thesauri," Library Technology Reports 48, no. 4 (2012): 27-36, dx.doi .org/10.5860/ltr.48n4

50. Julie Allinson, "OpenART: Open Metadata for Art Research at the Tate," Bulletin of the American Society for Information Science \& Technology 38, no. 3 (2012): 43-8, dx.doi .org/10.1002/bult.2012.1720380311.

51. Maria Nisheva-Pavlova and Pavel Pavlov, "Ontology-Based Search and Document Retrieval in a Digital Library with Folk Songs," Information Services \& Use 31, no. 3/4 (2011): 15766.

52. M. Cristina Pattuelli, "Modeling a Domain Ontology for Cultural Heritage Resources: A User-Centered Approach," Journal of the American Society for Information Science and Technology 62, no. 2 (2011): 314-42, dx.doi.org/10.1002/asi.21453.

53. Marjorie Hlava, "Developing an Eclectic Terminology Registry," Bulletin of the American Society for Information Science \& Technology 37, no. 4 (2011): 19-22, dx.doi.org/10.1002/ bult.2011.1720370406.

54. Jon Phipps and Diane Hillmann, "The Open Metadata Registry: An Update," Bulletin of the American Society for Information Science \& Technology 37, no. 4 (2011): 35-7, dx.doi .org/10.1002/bult.2011.1720370410.

55. Gordon Dunsire et al., "Linked Data Vocabulary Management: Infrastructure Support, Data Integration, and Interoperability," Information Standards Quarterly 24, no. 2/3 (2012): 4, dx.doi.org/10.3789/isqv24n2-3.2012.02.

56. Vanda Broughton, Essential Library of Congress Subject Headings, U.S. Editi (New York: Neal-Schuman Publishers, 2012).

57. Helen Greenblatt, "The Treatment of LGBTIQ Concepts in the Library of Congress Subject Headings," in Serving LBGTIQ Library and Archives Users, ed. Helen Greenblatt (Jefferson, N.C.: McFarland, 2011), 212-28; K. R. Roberto, "Inflexible Bodies," Journal of Information Ethics 20, no. 2 (September 01, 2011): 56-64, dx.doi.org/10.3172/JIE.20.2.56.

58. Deborah Lee, "Indigenous Knowledge Organization: A Study of Concepts, Terminology, Structure and (Mostly) Indigenous Voices," Partnership: The Canadian Journal of Library d Information Practice \& Research 6, no. 1 (2011): 1-33.

59. C. Rockelle Strader, "Citation Analysis," Library Resources \& Technical Services 56, no. 4 (2012): 238-53, dx.doi .org/10.5860//rts.56n4.238. 
60. John Porter, "Folksonomies in the Library: Their Impact on User Experience, and Their Implications for the Work of Librarians," Australian Library Journal 60, no. 3 (2011): 24855, dx.doi.org/10.1080/00049670.2011.10722621.

61. Getaneh Alemu, Brett Stevens, and Penny Ross, "Towards a Conceptual Framework for User-Driven Semantic Metadata Interoperability in Digital Libraries: A Social Constructivist Approach," New Library World 113, no. 1/2 (2012): 38-54, dx.doi.org/10.1108/03074801211199031.

62. Mary M. Somerville and Dana Echohawk, "Recuerdos Hablados/Memories Spoken: Toward the Co-Creation of Digital Knowledge with Community Significance," Library Trends 59, no. 4 (2011): 650-62, dx.doi.org/10.1353/lib.2011.0018.

63. Svein Anfinnsen, Gheorghita Ghinea, and Sergio de Cesare, "Web 2.0 and Folksonomies in a Library Context," International Journal of Information Management 31, no. 1 (February 2011): 63-70, dx.doi.org/10.1016/j.ijinfomgt.2010.05.006; Danielle H. Lee and Titus Schleyer, "Social Tagging Is No Substitute for Controlled Indexing: A Comparison of Medical Subject Headings and CiteULike Tags Assigned to 231,388 Papers," Journal of the American Society for Information Science and Technology 63, no. 9 (September 17, 2012): 1747-57, dx.doi.org/10.1002/asi.22653; Besiki Stvilia, Corinne Jörgensen, and Shuheng Wu, "Establishing the Value of Socially-Created Metadata to Image Indexing," Library o Information Science Research 34, no. 2 (April 2012): 99-109, dx.doi.org/10.1016/j.lisr.2011.07.011.

64. Christine DeZelar-Tiedman, "Exploring User-Contributed Metadata's Potential to Enhance Access to Literary Works," Library Resources \& Technical Services 55, no. 4 (2011): 22133, dx.doi.org/10.5860//rts.55n4.221.

65. Carrie Pirmann, "Tags in the Catalogue: Insights From a Usability Study of LibraryThing for Libraries," Library Trends 61, no. 1 (2012): 234-47, dx.doi.org/10.1353/lib.2012.0021.

66. Martha Fallahay Loesch, "The Virtual International Authority File," Technical Services Quarterly 28, no. 2 (2011): 255-56.

67. F. X. Nuttall and Sam G. Oh, "Party Identifiers," Cataloging of Classification Quarterly 49, no. 6 (2011): 528-37, dx.doi .org/10.1080/01639374.2011.603075.

68. Bob Thomas, "Name Disambiguation—Learning From More User-Friendly Models," Cataloging \& Classification Quarterly 49, no. 3 (2011): 223-32, dx.doi.org/10.1080/01639374.201 1.560834 .

69. David Bainbridge, Michael B. Twidale, and David M. Nichols, "Interactive Context-Aware User-Driven Metadata Correction in Digital Libraries," International Journal on Digital Libraries 13, no. 1 (2012): 17-32, dx.doi.org/10.1007/s00799 -012-0100-5.

70. Mohindar Partap Satija, "Brief Communication: Abridged Dewey-15 (2012) in Historical Perspectives," Knowledge Organization 39, no. 6 (2012): 466-68.

71. Mohindar Partap Satija, "The DDC 23rd Edition (2011): An Appraisal," SRELS Journal of Information Management 49, no. 1 (2012): 1-4.

72. Keith Trickey, “Maddeningly Dynamic," CILIP Update 10, no.
11 (2011): 44-5.

73. Rebecca Green, "See-Also Relationships in the Dewey Decimal Classification," Knowledge Organization 38, no. 4 (2011): 335-41.

74. Mathias Lösch et al., "Building a DDC-Annotated Corpus from OAI Metadata," JODI: Journal of Digital Information 12, no. 2 (2011): 1-9, accessed May 10, 2014, journals.tdl.org/jodi/ index.php/jodi/article/view/1765.

75. Arash Joorabchi and Abdulhussain E. Mahdi, "An Unsupervised Approach to Automatic Classification of Scientific Literature Utilizing Bibliographic Metadata," Journal of Information Science 37, no. 5 (2011): 499-514, dx.doi .org/10.1177/0165551511417785.

76. Colin Higgins, "Library of Congress Classification: Teddy Roosevelt's World in Numbers?," Cataloging \& Classification Quarterly 50, no. 4 (2012): 254, dx.doi.org/10.1080/01639374 .2012.658989.

77. Ibid., 254.

78. Sherman Clarke, "Class N, or, Classifying the Fine Arts Using the Library of Congress Classification," Art Libraries Journal 36 , no. 4 (2011): 22-5.

79. Deborah Lee, "Dealing with Adaptation: The Courtauld Classification Scheme," Art Libraries Journal 36, no. 4 (2011): 26-33.

80. Carlo Bianchini, "Arrangement of FRBR Entities in Colon Classification Call Numbers," Cataloging \& Classification Quarterly 50, no. 5-7 (2012): 473-93, dx.doi.org/10.1080/016 39374.2012.679877.

81. Maria White, "Brackets and Flying Commas: UDC in Tate Library," Art Libraries Journal 36, no. 4 (2011): 13-17.

82. Keith C. Mages, "The Bellevue Classification System: Nursing's Voice Upon the Library Shelves," Journal of the Medical Library Association 99, no. 1 (2011): 40-50, dx.doi .org/10.3163/1536-5050.99.1.008.

83. Ibid., 48.

84. Erin Stalberg and Christopher Cronin, "Assessing the Cost and Value of Bibliographic Control," Library Resources \& Technical Services 55, no. 3 (2011): 124-37, dx.doi .org/10.5860//rts.55n3.124.

85. Library of Congress Working Group on the Future of Bibliographic Control, On the Record: Report of the Library of Congress Working Group on the Future of Bibliographic Control, 2008, accessed May 10, 2014, www.loc.gov/biblio graphic-future/news/lcwg-ontherecord-jan08-final.pdf.

86. Giuliano Genetasio, "The International Cataloguing Principles and Their Future," Italian Journal of Library \& Information Science 3, no. 1 (2012): 4936.1-17, dx.doi.org/10.4403/ jlis.it-4936.

87. Michele Seikel and Thomas Steele, "How MARC Has Changed: The History of the Format and Its Forthcoming Relationship to RDA," Technical Services Quarterly 28, no. 3 (2011): 322-34, dx.doi.org/10.1080/07317131.2011.574519.

88. Francis Miksa, "The Legacy of the Library Catalogue for the Present," Library Trends 61, no. 1 (2012): 7-34, dx.doi .org/10.1353/lib.2012.0023. 
89. Joan C. Biella and Heidi G. Lerner, "The RDA Test and Hebraica Cataloging: Applying RDA in One Cataloging Community," Cataloging \& Classification Quarterly 49, no. 7-8 (2011): 676-95, dx.doi.org/10.1080/01639374.2011.616450.

90. Yoko Kudo, "Modified Hepburn Romanization System in Japanese Language Cataloging: Where to Look, What to Follow," Cataloging \& Classification Quarterly 49, no. 2 (2011): 97-120, dx.doi.org/10.1080/01639374.2011.536751.

91. Geoff Husic, "Romani Language: Cataloging Ramifications for a Language in the Process of Standardization," Slavic \& East European Information Resources 12, no. 1 (2011): 37-51, dx.doi.org/10.1080/15228886.2011.556076.

92. Peter H. Lisius and Richard Griscom, eds., Directions in Music Cataloging (Middleton, WI: Music Library Association, 2012).

93. Gail Thornburg and W. Michael Oskins, "Matching Music: Clustering Versus Distinguishing Records in a Large Database," OCLC Systems \& Services 28, no. 1 (2012): 32-42, dx.doi.org/10.1108/10650751211197059.

94. Jenn Riley, "Leveraging the FRBR Model for Music Discovery and Data Sharing: Autobiographical Note," OCLC Systems \& Services 27, no. 3 (2011): 175-89, dx.doi .org/10.1108/10650751111164551; Jenn Riley, "Scherzo Music Discovery System at Indiana University," Cataloging o Classification Quarterly 49, no. 2 (2011): 144, dx.doi.org/10.1080/ 01639374.2011 .544054 .

95. FontesArtisMusicae 59 no. 3 (2012, Special Issue).

96. Jean Harden, "Cataloguing in 2012: On the Cusp of RDA," Fontes Artis Musicae 59, no. 3 (2012): 253.

97. Anders Cato, "Music Cataloguing in Europe and RDA: Current Practises Challenged by New Rules," Fontes Artis Musicae 59, no. 3 (2012): 270-85.

98. Mark McKnight, "Are We There Yet? Toward a Workable Controlled Vocabulary for Music," Fontes Artis Musicae 59, no. 3 (2012): 286-92.

99. Margaret Beecher Maurer, Sevim McCutcheon, and Theda Schwing, "Who's Doing What? Findability and Author-Supplied ETD Metadata in the Library Catalog," Cataloging o Classification Quarterly 49, no. 4 (2011): 277-310, dx.doi.org/ 10.1080/01639374.2011.573440.

100. Ibid., 306.

101. Rachel I. Howard and Tyler Goldberg, "Facilitating Greater Access to ETDs Through CONTENTdm," OCLC Systems \& Services 27, no. 2 (2011): 113-23, dx.doi .org/10.1108/10650751111135418.

102. Barbara Schultz-Jones et al., "Historical and Current Implications of Cataloguing Quality for Next-Generation Catalogues," Library Trends 61, no. 1 (2012): 49-82, dx.doi .org/10.1353/lib.2012.0028.

103. Ibid., 78 .

104. Joshua Barton and Lucas Mak, "Old Hopes, New Possibilities: Next-Generation Catalogues and the Centralization of Access," Library Trends 61, no. 1 (2012): 83-106, dx.doi .org/10.1353/lib.2012.0030.
105. Myung-Ja Han, "New Discovery Services and Library Bibliographic Control," Library Trends 61, no. 1 (2012): 162-72, dx.doi.org/10.1353/lib.2012.0025; Tonia Graves and Angela Dresselhaus, "One Academic Library-One Year of WebScale Discovery,” Serials Librarian 62, no. 1-4 (2012): 169-75; Jeffrey Daniels and Patrick Roth, "Incorporating Millennium Catalog Records into Serials Solutions' Summon," Technical Services Quarterly 29, no. 3 (2012): 193-99, dx.doi.org/10.108 0/07317131.2012.681283.

106. Susan C. Wynne and Martha J. Hanscom, "The Effect of NextGeneration Catalogs on Catalogers and Cataloging Functions in Academic Libraries," Cataloging \& Classification Quarterly 49, no. 3 (2011): 179-207, dx.doi.org/10.1080/01639374.20 11.559899 .

107. Pamela Harpel-Burke, "Catalog Maintenance in the Discovery System: Opinions of Early Adopters," College \& Undergraduate Libraries 19, no. 2-4 (2012): 246-63, dx.doi.org/10 $.1080 / 10691316.2012 .693363$.

108. Larisa Walsh, "The Faceted Catalog as a Tool for Searching Monographic Series: Usability Study of Lens," Cataloging \& Classification Quarterly 50, no. 1 (2012): 43-59, dx.doi.org/10.1080/01639374.2011.610433; William Denton and Sarah J. Coysh, "Usability Testing of VuFind at an Academic Library," Library Hi Tech 29, no. 2 (2011): 30119, dx.doi.org/10.1108/07378831111138189; Debra G. Skinner, "A Comparison of Searching Functionality of a VuFind Catalogue Implementation and the Traditional Catalogue," Library Trends 61, no. 1 (2012): 208-17, dx.doi.org/10.1353/ lib.2012.0031.

109. Kathleen Bauer and Alice Peterson-Hart, "Does Faceted Display in a Library Catalog Increase Use of Subject Headings?," Library Hi Tech 30, no. 2 (2012): 347-58, dx.doi .org/10.1108/07378831211240003.

110. Ibid., 354 .

111. Steven J. Miller, Metadata for Digital Collections: A How To Do It Manual (New York: Neal-Schuman, 2011).

112. Ditte Laursen, Kåre Fiedler Christiansen, and Lars Lundegård Olsen, "Management of Metadata for Digital Heritage Collections," Microform \& Digitization Review 41, no. 3-4 (2012): 151-58, dx.doi.org/10.1515/mir-2012-0024.

113. Kristin E. Martin, "Marrying Local Metadata Needs With Accepted Standards: The Creation of a Data Dictionary at the University of Illinois at Chicago," Journal of Library Metadata 11, no. 1 (2011): 33-50, dx.doi.org/10.1080/19386389.201 1.545006; Silvia B. Southwick and Cory Lampert, "Metadata Dictionary Database: A Proposed Tool for Academic Library Metadata Management," Journal of Electronic Resources Librarianship 23, no. 4 (2011): 339-60, dx.doi.org/10.1080/19 41126X.2011.627053.

114. Maureen P. Walsh, "Repurposing MARC Metadata for an Institutional Repository: Working with Special Collections and University Press Monographs," Library Resources \& Technical Services 55, no. 1 (2011): 33-44.

115. Tracy Guza, "The Seattle Public Library Century 21 Collection: 
Balancing Metadata Complexity, Processing Expediency, and User Experience," PNLA Quarterly 75, no. 3 (2011): 92-104; Mark A. Greene and Dennis Meissner, "More Product, Less Process: Revamping Traditional Archival Processing," American Archivist 68, no. 2 (2005): 208-63.

116. Renée McBride, "Look What We Got! How Inherited Data Drives Decision-Making: UNC-Chapel Hill's 19th-Century American Sheet Music Collection," Code4Lib Journal, no. 13 (2011): 1-20, accessed May 10, 2014, journal.code4lib.org/ articles/4916.

117. Cynthia Tobar, "Music to My Ears: The New York Philharmonic Digital Archives," D-Lib Magazine 17, no. 7/8 (2011), dx.doi.org/10.1045/july2011-tobar.

118. R. Niccole Westbrook et al., "Metadata Clean Sweep: A Digital Library Audit Project," D-Lib Magazine 18, no. 5/6 (2012), dx.doi.org/10.1045/may2012-westbrook.

119. Shirley Lim and Chern Li Liew, "Metadata Quality and Interoperability of GLAM Digital Images," Aslib Proceedings: New Information Perspectives 63, no. 5 (2011): 484-98, dx.doi .org/10.1108/00012531111164978.

120. Baker, "Libraries, Languages of Description, and Linked Data: A Dublin Core Perspective, 128."

121. Rebecca L. Mugridge and Jeff Edmunds, "Batchloading MARC Bibliographic Records: Current Practices and Future Challenges in Large Research Libraries," Library Resources \& Technical Services 56, no. 3 (2012): 155-70, dx.doi .org/10.5860//rts.56n3.155.

122. Philip Young, "A Survey of Batch Cataloging Practices and Problems," Technical Services Quarterly 29, no. 1 (November 18, 2012): 22-41, 10.1080/07317131.2012.624450.

123. Kristy L. Dixon and Lisa T. Nickel, "MetaWHAT?: Training Access Services Staff to Partner in Digital Projects Metadata Creation," College \& Research Libraries News 73, no. 2 (2012): 74-82, accessed May 10, 2014, crln.acrl.org/content/ $73 / 2 / 74$.

124. Gwen Evans and Kellie Tilton, "Creating an Un-Library Catalog: A Case Study in Managing Satellite Collections," Library Resources \& Technical Services 55, no. 1 (2011): 45-53, dx.doi .org/10.5860//rts.55n1.45.

125. Teressa M. Keenan, "Charting a Course With NOMAP: Integrating Metadata Workflows Into a Traditional Cataloging Unit," Journal of Library Metadata 12, no. 2-3 (2012): 199212, dx.doi.org/10.1080/19386389.2012.699842.

126. Ibid., 210.

127. Carrie A. Preston, "Cooperative E-Book Cataloging in the OhioLINK Library Consortium," Cataloging \& Classification Quarterly 49, no. 4 (2011): 257-76, dx.doi.org/10.1080/01639 374.2011.571147.

128. Kristin E. Martin et al., "Consortial Cataloging Guidelines for Electronic Resources: I-Share Survey and Recommendations," Cataloging \& Classification Quarterly 49, no. 5 (June 2011): 361-86, dx.doi.org/10.1080/01639374.2011.588996.

129. Rogan Hamby, " $10 \%$ Wrong for $90 \%$ Done: A Practical Approach to Collection Deduping," Computers in Libraries
32 , no. 4 (2012): 17-21.

130. Sara Rofofsky Marcus, “An Interview with Joseph Miller," Cataloging \& Classification Quarterly 49, no. 2 (2011): 136-37, dx.doi.org/10.1080/01639374.2011.545343.

131. Steven J. Miller et al., "Online Cataloging Education at the University of Wisconsin-Milwaukee," Cataloging \& Classification Quarterly 50, no. 2-3 (February 2012): 110-26, dx.doi .org/10.1080/01639374.2011.651193.; Kathryn La Barre, K. R. Roberto, and Faye Leibowitz, "The Common Gaze: Conversations with Cataloging Instructors about Teaching Online at the Graduate School of Library and Information Science, University of Illinois at Urbana-Champaign," Cataloging \& Classification Quarterly 50, no. 2-3 (February 2012): 12743, dx.doi.org/10.1080/01639374.2011.650840; Janet Swan Hill, "The Brick Wall: Attracting People to a Career in Cataloging," in Conversations with Catalogers in the 21st Century, ed. Elaine R. Sanchez (Santa Barbara, CA: Libraries Unlimited, 2011), 209-18; Sylvia D. Hall-Ellis, "Cataloging/Metadata and Library Science Education Programs for Catalogers and Metadata Specialists: Challenges for the Twenty-First Century," in Conversations with Catalogers in the 21st Century, ed. Elaine R. Sanchez (Santa Barbara, CA: Libraries Unlimited, 2011), 226-54; Cataloging \& Classification Quarterly 50, no. 2-3: (special issue, 2012).

132. Cataloging and Classification Quarterly 50, no. 2-3 (2012).

133. "The Common Gaze: Conversations with Cataloging Instructors about Teaching Online at the Graduate School of Library and Information Science, University of Illinois at UrbanaChampaing," Cataloging \& Classification Quarterly, 50, no. 2-3 (2012): 127-43, dx.doi.org/10.1080/01639374.20111.6508 40; Gretchen L. Hoffman, "Using the Quality Matters Rubric to Improve Online Cataloging Courses," Cataloging \& Classification Quarterly 50, no. 2-3 (2012): 158-71, dx.doi.org/1 0.1080.01639372.2011.651194; Morag Boyd,"From the Comfort of Your Office: Facilitating Learner-Centered Continuing Education in the Online Environment," Cataloging of Classification Quarterly 50, no. 2-3 (2012): 189-203, dx.doi.org/10 $.1080 / 01639374.2011 .651195$.

134. Natalia Gelber and Irina Kandarasheva, "PCC Training for Copy Catalogers: Is It Worth the Investment? The Columbia University Libraries Experience," Library Resources \& Technical Services 55, no. 3 (2011): 163-71, dx.doi.org/10.5860/ lrts.55n3.163.

135. Gretchen L. Hoffman, "Could the Functional Future of Bibliographic Control Change Cataloging Work? An Exploration Using Abbott," Journal of Library Metadata 12, no. 2-3 (2012): 111-26, dx.doi.org/10.1080/19386389.2012.699825.

136. Michael A. Cerbo, "Is There a Future for Library Catalogers?," Cataloging \& Classification Quarterly 49, no. 4 (2011): 323-27, dx.doi.org/10.1080/01639374.2011.571504.

137. Schreur, “The Academy Unbound,” 232.

138. Hoffman, "Could the Functional Future of Bibliographic Control Change Cataloging Work?," 124. 